Original article

\title{
HEALING OF EXPERIMENTAL FEMORAL DEFECTS IN RATS AFTER IMPLANTATION OF COLLAGEN-CALCIUM PHOSPHATE BIOCOMPOSITES
}

\author{
O. V. KORENKOV \\ Department of Human Anatomy, Sumy State University, Ukraine
}

\begin{abstract}
Summary
Korenkov, O. V., 2017. Healing of experimental femoral defects in rats after implantation of collagen-calcium phosphate biocomposites. Bulg. J. Vet. Med., 20, No 2, 151-160.

The aim of this study was to investigate the healing process of experimental defects of the femoral shaft diaphysis of rats after implantation of osteoplastic material Collapan into its cavity. In experimental animals, a perforated defect with diameter of $2.5 \mathrm{~mm}$ was created in the medullary canal of the femoral shaft and filled with osteoplastic material Collapan. In control rats, the defect was left unfilled. The bone fragments were examined on the $15^{\text {th }}$ and $30^{\text {th }}$ day by light microscopy morphometry and scanning electron microscopy. It was found that application of osteoplastic material Collapan in the femoral diaphysis defect optimised reparative osteogenesis, showed high biocompatibility, osteoconductive properties, resorption ability and good integration with tissue-specific structures of the regenerate.
\end{abstract}

Key words: bone, Collapan, rats, reparative osteogenesis

\section{INTRODUCTION}

Transplantation of bone tissue for bone defects replacement has a long history, during which considerable success has been achieved. The high incidence of complications that may arise after such operations, the interest in the calciumphosphate osteoplastic materials and their combinations with collagen has increased in recent years (Germanov et al., 2006).

Approximately $70 \%$ of bone tissue mineral component is represented by hydroxyapatite (which is calcium phosphate), and $95 \%$ of the whole organic part of bone matrix is type I collagen (Pankra- tov et al., 2011). Thanks to this, the biological compatibility of hydroxyapatite and other calcium phosphate osteoplastic materials with bone tissue is almost ideal and together with collagen they are able to undergo resorption without formation of by-products (Barinov \& Komlev, 2005). Besides biocompatibility, calcium phosphate osteoplastic materials have inherent osteoconductive, osteostimulating and secondary osteoconductive variants of influence on reparative osteogenesis (Dorozhkin, 2015). In contrast, collagen exerts a haemostatic effect in the wound, which is 
caused by aggregation on its surface of platelets, promotes vascularisation of tissues and increases the proliferation of fibroblasts (Park \& Bronzino, 2003). Type I collagen, together with hydroxyapatite and other calcium phosphate ceramics have optimum mechanical properties, can be used as carriers of pharmacological drugs, biologically active substances and can even have osteoconductive influence on reparative osteogenesis (Pankratov et al., 2011; Dorozhkin, 2013). Thus, the combination of hydroxyapatite and collagen provides osteoplastic materials that are more close in structure, mechanical and other properties to the bone tissue than their components separately.

A preparation consisting of nanostructured hydroxyapatite, of collagen type I from skin of cattle and antibiotics (lincomycin, gentamicin, etc.) is Collapan (Intermedapatyt, Russia), used extensively in the clinical practice since 1995. During this time, it has shown a high biocompatibility, antimicrobial activity (due to the presence of antibiotic in its composition) and other great features for treatment of bone defects in orthopaedics, traumatology, spinal surgery, dentistry and maxillofacial surgery (Barer et al., 2004; Snetkov et al., 2006; Kavalersky et al., 2013).

However, despite the sufficiency of works that demonstrate the safety and biocompatibility of Collapan, other properties of osteoplastic material, such as dynamics and its rate of biodegradation, replacement by the newly created bone tissue exhibited significant data divergence. So, Berchenko et al. (2006), without specifying morphometric parameters, reported an almost complete recovery of the defect with fine residues of particles of the implant by the $90^{\text {th }}$ day of the experiment, and Bushuyev (1999) - complete resorption of osteoplastic material and defect recovery within 6 months after the Collapan implantation into the diaphysis defect of the femoral shaft of rats (Bushuyev, 1999; Berchenko et al., 2006). On the $21^{\text {st }}$ and $35^{\text {th }}$ day after Collapan implantation into the perforated defect of the diaphysis of the radial bone of rabbits, Semenyak et al. (2015) described gradual resorption of the osteoplastic material and its replacement by connective and wooven bone tissue, but also without performing morphometry. In addition, the review of literature showed that the majority of works devoted to the research of Collapan were aimed at establishing radiological, biochemical and histological dynamics of bone defects healing, without providing morphometric parameters and electron microscopic characteristics of tissue-specific structures of the regenerate (Iordanishvili et al., 2002; Rublenko \& Semenyak, 2014; Semenyak, 2014).

Therefore, the aim of our work was to explore the healing process of experimental defects of the femoral diaphysis of rats after implantation of osteoplastic material Collapan using histological, morphometric and electron microscopy methods.

\section{MATERIALS AND METHODS}

The experiment was performed on 48 albino Wistar rats, eight months of age with a body weight of $250 \pm 10 \mathrm{~g}$. All procedures were given agreement from the Commission on Biomedical Ethics of Sumy State University (permit 4/14 of 18.06.2015). The study protocol was compliant to the provisions of European Community Directive of 24 November 1986 on the maintenance and use of laboratory animals for research purposes. Before surgery, animals were initially injected with $2.5 \mathrm{mg} / \mathrm{kg}$ acepromazine, and after $5 \mathrm{~min}$, with $75 \mathrm{mg} / \mathrm{kg}$ of ketamine 
(Calypsol, Gedeon Richter, Hungary). After the induction of the animals in anaesthesia, a defect of the medullary canal with diameter of $2.5 \mathrm{~mm}$ was reproduced under aseptic conditions in the middle third of the femoral diaphysis using a portable drill with a spherical cutter at low speed with cooling.

Further, the experimental animals were divided into 2 groups:

- Group 1 (24 rats) - control, where the bone defect was left to heal under blood clot;

- Group 2 (24 rats) - experimental, where the defect without rigid fixation was filled with the osteoplastic material Collapan (registration number 2011/10304 FES Intermedapatyt, Russia) (Fig. 1).

Next, on the $15^{\text {th }}$ and $30^{\text {th }}$ day post surgery, the animals were sacrificed by decapitation under deep ether anaesthesia, followed by a study of injured bones by light microscopy morphometry and scanning electron microscopy.

For light microscopy, we extracted the fragments of femoral bones from the site of implantation of osteoplastic material and fixed them in $10 \%$ neutral formalin. After washing with water, the bone samples were subjected to decalcification in $5 \%$ aqueous solution of Trilon B, dehydrated in ascending alcohol seres and embedded in paraffin. Histological sections were made with a Reichert microtome, stained with haematoxylin-eosin, analysed by Olympus light microscope and photographed by digital camera.

Morphometric analysis consisted in determination of the areas of bone and connective tissues, and remnants of osteoplastic material at the site of the defect using the image processing software "Video-Test" and "Video-Size".

For scanning electron microscopy, femoral fragments from implanted material were extracted and placed in glutaraldehyde holder. Next day the samples were washed in phosphate buffer, fixed in $1 \%$ $\mathrm{OsO}_{4}$ solution and dehydrated in increasing ethanol series. Further, the bone fragments were glued on metal tables with electrically conductive adhesive, sprayed with carbon dust in standard VUP-5 type vacuum installation and examined with an electron microscope SEM 106-I.

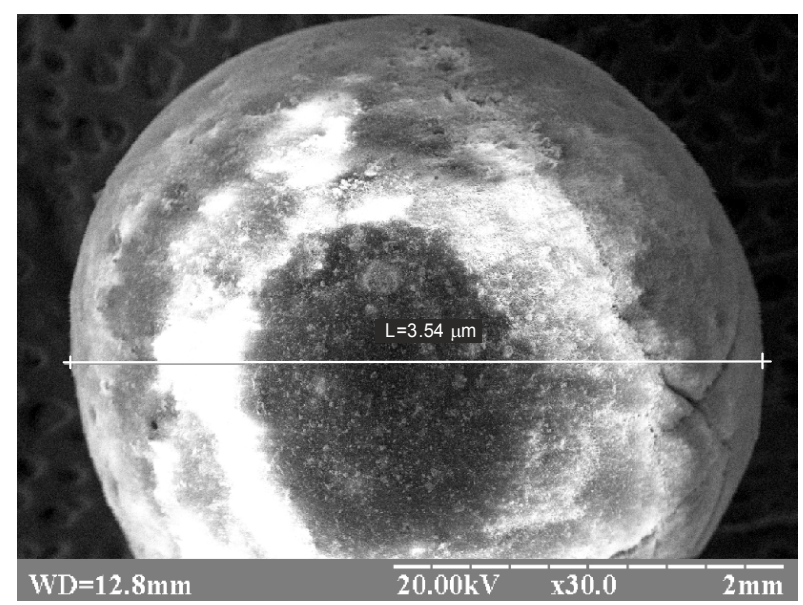

Fig. 1. SEM of a granule of the osteoplastic material Collapan $(3.54 \mu \mathrm{m}$ of size $) \times 30$. 
Healing of experimental femoral defects in rats after implantation of collagen-calcium phosphate....

Using light and scanning electron microscopy morphological characteristics of newly formed tissue-specific structures of the regenerate, the nature of their interaction with osteoplastic material Collapan were established. In addition, by using these methods, we investigated the structure of maternal bone adjacent to the implantation site in order to detect postoperative complications due to the presence or absence of signs of necrobiosis and necrosis of osteocytes (Grigorian \& Toporkova, 2007).

The numerical values (mean and standard error of the mean) were statistically analysed using Student $t$-test (MS Excel $\mathrm{XP}$ ). The differences were considered significant at $\mathrm{P}<0.05$ (Lapach et al., 2000).

\section{RESULTS}

In control animals, elements of boneconnective callus, which consisted on $47.66 \pm 2.3 \%$ of wooven bone tissue and on $52.34 \pm 2.3 \%$ of connective tissue were established on the $15^{\text {th }}$ day of the experi- ment in the area of the defect (Fig. 2). In experimental animals the defect was also filled with bone and connective tissues of the regenerate, but the latter were formed directly on the surface of osteoplastic material Collapan, dissected its granules into separate small fragments and immured them in their structures. In the animals of both groups, the bone tissue of regenerate was represented by bone trabeculae, which formed the small- and large-looped mesh structures, in the structure of which numerous osteoblasts and osteocytes were identified. In this case the bone tissue in experimental rats occupied $55.46 \pm 2.56 \%$ of the entire area of the defect, which was by $16.36 \% \quad(\mathrm{P}>0.05)$ higher than in the animals of control group. Intertrabecular space in controls was filled with connective tissue and in the experimental animals - with connective tissue and a small number of osteoplastic material. The latter, after haematoxylin-eosin staining, appeared like a gray unstructured mass and occupied $25.48 \pm 1.4 \%$ of the total area of the defect. Inside the implant there were

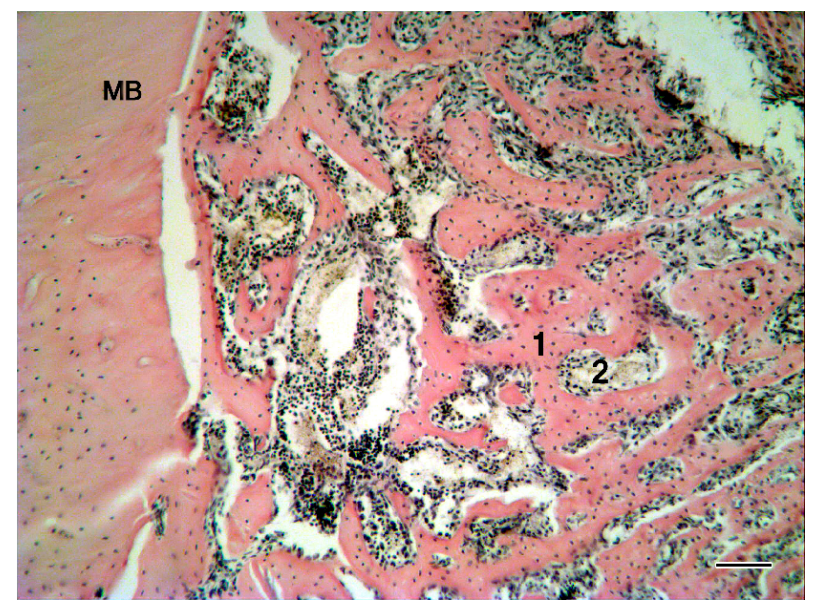

Fig. 2. The site of femoral bone defect of a control rat, $15^{\text {th }}$ day. Maternal bone (MB) with typical osteocytes in its composition. Wooven bone tissue of regenerate (1), in whose intertrabecular space connective tissue is located (2). $\mathrm{H} / \mathrm{E}$; bar $=40 \mu \mathrm{m}$. 


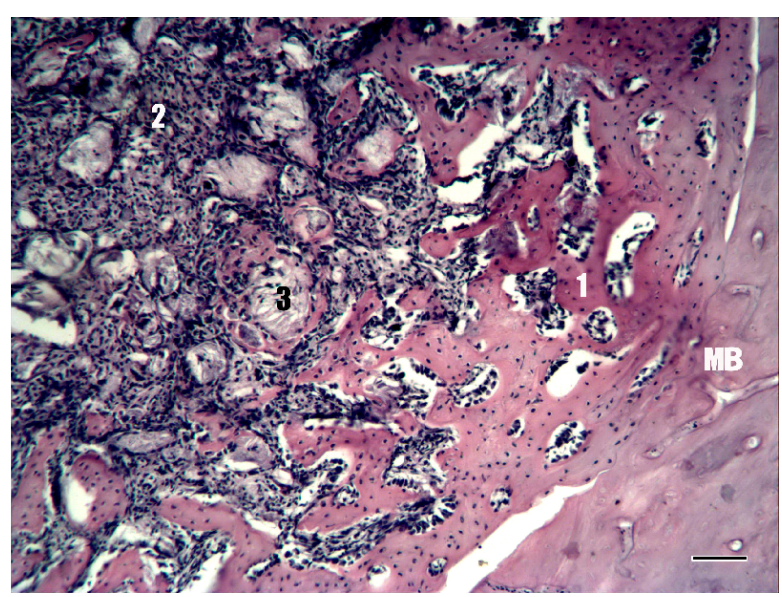

Fig. 3. The site of the femoral bone defect, $15^{\text {th }}$ day after the Collapan implantation. At the edges of maternal bone (MB) there is wooven bone tissue (1), and at a distance from it, connective tissue prevails (2), in the structure of which there are particles of implanted material (3). H/E; bar=40 $\mu \mathrm{m}$.

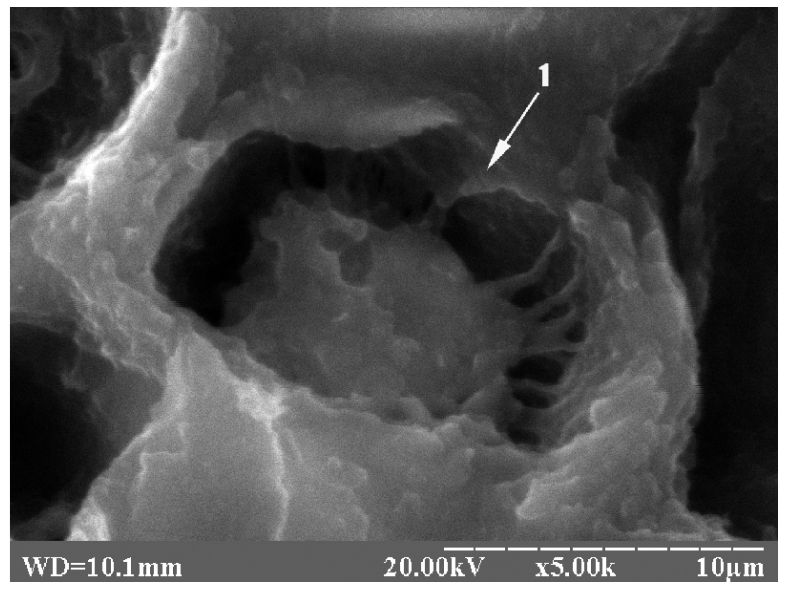

Fig. 4. SEM of the site of the femoral bone defect, $15^{\text {th }}$ day after the Collapan implantation. Osteocytes (1) in the wooven bone tissue that surrounds the particles of osteoplastic material. $\times 2500$.

fibro- and osteoblastic cell elements, which formed small foci of fibro- and osteogenesis. It should also be noted that in the peripheral parts of defects from both groups, the bone tissue of the regenerate predominated while in the central part - the connective tissue, made up from a large number of fibroblasts, collagen fibres and blood vessels. In experimental animals the connective tissue contained in its composition particles of implanted material (Fig. 3, 4), and its amount was by $63.58 \%(\mathrm{P}<0.05)$ lower than that in control rats and comprised $19.06 \pm 1.13 \%$ of the total area of the defect.

In all animals there were no signs of inflammation in the area of the defect. Adjacently to the site of the defect, mater- 
Healing of experimental femoral defects in rats after implantation of collagen-calcium phosphate....

nal bone was characterised by the presence of bone lacunae with typical osteocytes.

On the $30^{\text {th }}$ day of the experiment the site of the defect was filled with bone tissue of the regenerate, which, compared to the previous period of observation in con- trol animals, increased by $59.25 \%$ $(\mathrm{P}<0.05)$, and in the experimental group by $24.7 \%(\mathrm{P}<0.05)$ and attained $75.9 \pm$ $2.72 \%$ in the former and $69.16 \pm 2.9 \%$ in the latter case. Mainly in the central parts of the defect there were newly formed trabeculae of wooven bone tissue, whose

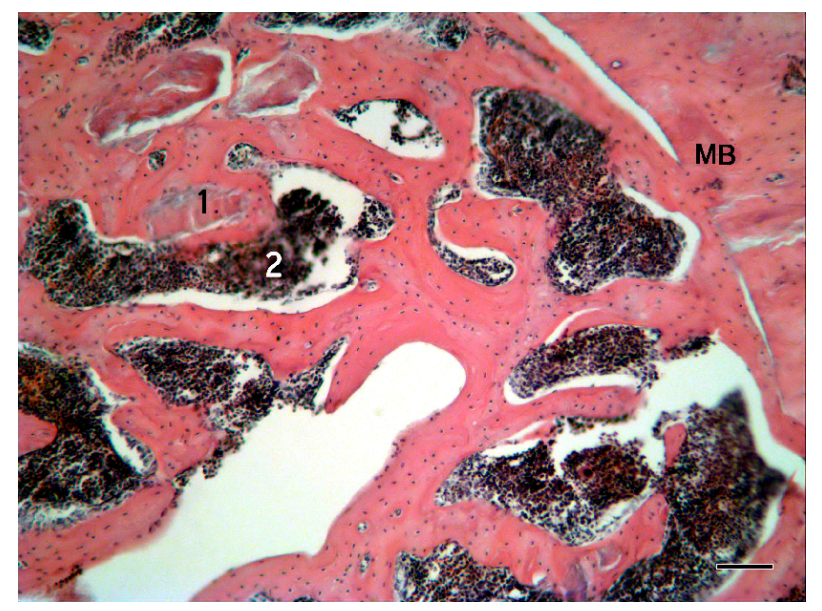

Fig. 5. The site of femoral bone defect of a control rat, $30^{\text {th }}$ day. Maternal bone (MB) adjacent to the implantation site. Bone tissue of the regenerate, in whose intertrabecular space bone marrow is located (2). H/E; bar=40 $\mu \mathrm{m}$.

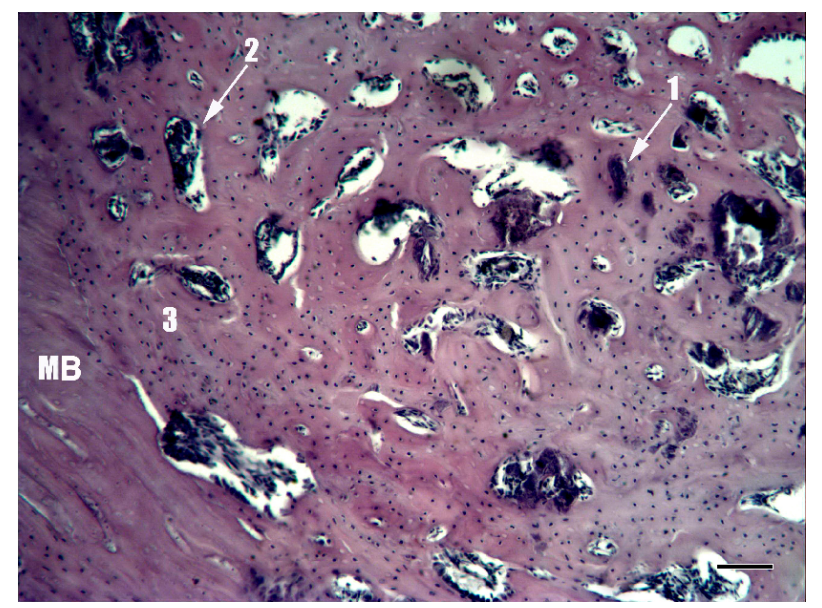

Fig. 6. The site of the femoral bone defect, $30^{\text {th }}$ day after the Collapan implantation. Remnants of osteoplastic material (1) and connective tissue with the implant (2) integrated into the bone tissue of the regenerate (3), which tightly adjoins to the edge of the maternal bone (MB). H/E; bar $=40 \mu \mathrm{m}$. 
O. V. Korenkov

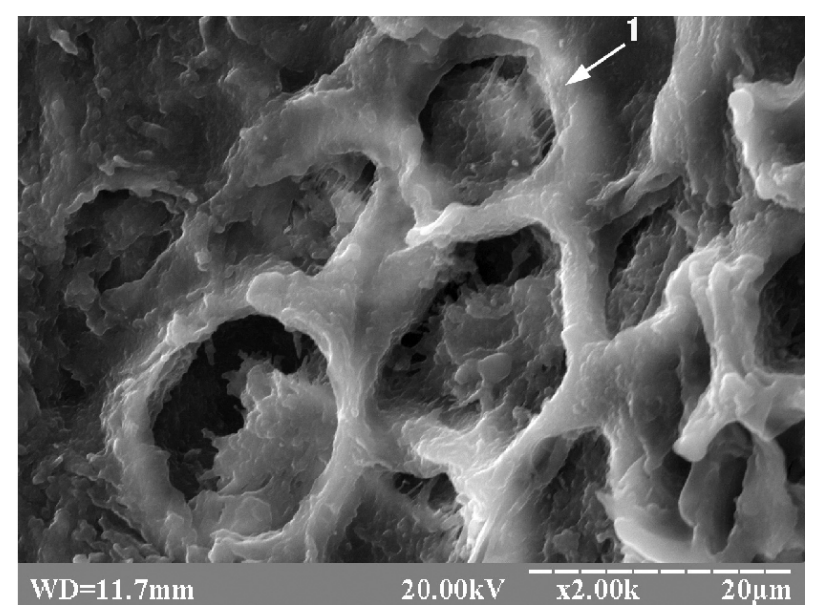

Fig. 7. SEM of the site of the femoral bone defect, $30^{\text {th }}$ day after the Collapan implantation. Osteoblasts (1) in the wooven bone tissue that is formed on the surface of osteoplastic material., $\times 2000$.

Table 1. Relative area (\%) of tissues of the regenerate and osteoplastic material in the femoral diaphyseal defect (mean \pm SEM; $\mathrm{n}=12$ )

\begin{tabular}{llcc}
\hline \multirow{2}{*}{$\begin{array}{l}\text { Day after } \\
\text { implantation }\end{array}$} & & \multicolumn{2}{c}{ Groups } \\
\cline { 3 - 4 } & & Experimental & Control \\
\hline \multirow{3}{*}{15} & Connective tissue & $19.06 \pm 1.13$ & $52.34 \pm 2.3^{*}$ \\
& Bone tissue & $55.46 \pm 2.56$ & $47.66 \pm 2.3$ \\
& Collapan & $25.48 \pm 1.4$ & - \\
\hline \multirow{3}{*}{30} & Connective tissue & $14.45 \pm 1.1$ & - \\
& Bone tissue & $69.16 \pm 2.9$ & $75.9 \pm 2.72$ \\
& Collapan & $16.39 \pm 0.93$ & - \\
\hline
\end{tabular}

* significant difference between the experimental and control group $(\mathrm{P}<0.05)$.

intertrabecular space of in controls was filled with the bone marrow, and in experimental animals - with the remnants of osteoplastic material and connective tissue of the regenerate (Fig. 5,6).

In the peripheral parts of the defect of all animals, predominated the lamellar bone tissue with formed osteons, osteoblasts and osteocytes (Fig. 7). However, the bone tissue of experimental animals differed from that in control ones by the presence of remnants of Collapan in- tegrated into its structure, inside and on the outer surface of which there were osteogenic cell elements. In this case, there were areas of direct contact between bone tissue and osteoplastic material, as well as sites where the connective tissue layers were located between them.

As compared to the $15^{\text {th }}$ day (Table 1), the area of osteoplastic material decreased by $35.67 \%(\mathrm{P}<0.05)$, and that of connective tissue - by $24.18 \%(\mathrm{P}<0.05)$ and was $16.39 \pm 0.93 \%$ in the first and $14.45 \pm 1.1 \%$ 
in the second case. It should also be noted that on the $30^{\text {th }}$ day of the experiment, similarly to the previous period of observation, there were no signs of inflammation in the area of the defect both in control and experimental groups. Maternal bone adjacent to the site of the defect was characterised by the presence of typical osteocytes in its structure.

\section{DISCUSSION}

The conducted microscopic examination of the femoral diaphysis defects of rats after implantation of osteoplastic material Collapan showed that the latter had a high biocompatibility, as evidenced by the absence of an inflammatory reaction in the area of the defect and the lack of necrosis and necrobiosis of maternal bone osteocytes adjacently to the site of implantation. These results are consistent with the data of most researchers (Barer et al., 2004; Berchenko et al., 2006; Snetkov et al., 2006; Pankratov et al., 2011; Kavalersky et al., 2013). In addition, this experimental study revealed the high tropism of osteogenic cells to osteoplastic material, located on the surface and inside Collapan particles forming there small foci of osteoand fibrogenesis was established. It is known that the osteoplastic material, which provides the necessary support for the cells to attach, gives them the opportunity to divide and differentiate in the osteogenic direction. Therefore, the use of the osteoplastic material by the osteogenic cells as a platform for attachment and generation of new bone tissue on the surface and in its cavities is the proof of its osteoconductive properties (Jenkins, 2011).

In the area of the defect of animals of both groups, the microscopic examination also demonstrated signs of desmal osteogenesis only, as evidenced by their pres- ence in the bone and the connective tissues, and the absence of the cartilaginous one. Here, the Collapan granules dissected into individual particles were very well integrated with tissue-specific structures of the regenerate, as evidenced by the formation of bone and connective tissue directly on the surface of osteoplastic material and their close immurement in their structures. However, other studies showed that on the $30^{\text {th }}$ day after Collapan implantation in rat tibial epiphyseal defect, there were particles of the osteoplastic material, on the surface of which only bone tissue was formed, without layers of connective tissue between them (Berchenko et al., 2006). In our study, we observed a new bone tissue formation and maturation directly on the surface of Collapan, but a part of the osteoplastic material was integrated into the connective tissue of the regenerate as well.

We should also note that the majority of works devoted to the study of Collapan demonstrated its ability of resorption and replacement by the bone tissue (Barer et al., 2004; Berchenko et al., 2006; Snetkov et al., 2006; Pankratov et al., 2011; Kavalersky et al., 2013; Semenyak et al., 2015). However, morphometric data of the studied parameters are not found in the literature. In our experiment, we also observed gradual resorption of the osteoplastic material and its substitution by tissuespecific structures of the regenerate. Here, the morphometric method has given another opportunity to establish the dynamics of changes in the amount of the implant, bone and connective tissues, the ratio of which on the $15^{\text {th }}$ day of the experiment was $25.48 \pm 1.4 \%$ to $55.46 \pm 2.56 \%$ and $19.06 \pm 1.13 \%$, and the $30^{\text {th }}$ day $-16.39 \pm 0.93 \%$ to $69.16 \pm 2.9 \%$ and $14.45 \pm 1.1 \%$. Comparing the morphometric parameters, we can note that 
despite the fact that $25.48 \pm 1.4 \%$ of the entire area of the defect was occupied by osteoplastic material, on the $15^{\text {th }}$ day there was a fewer amount of connective tissue $(19.06 \pm 1.13 \%$ vs $52.34 \pm 2.3 \% ; \quad \mathrm{P}<0.05)$ in experimental animals and simultaneously, a bigger amount of bone tissue $(55.46 \pm 2.56 \%$ vs $47.66 \pm 2.3 \% ; \quad \mathrm{P}>0.05)$ compared to control animals. This was a clear evidence about the beneficial effect of Collapan on reparative osteogenesis. However, on the $30^{\text {th }}$ day, the amount of bone tissue in experimental animals was insignificantly lower $(69.16 \pm 2.9 \%$ vs $75.94 \pm 2.72 \%$ in control ones) and there remained a small connective tissue amount $(14.45 \pm 1.1 \%)$, whereas in the animals of the control group it was already absent. Despite the fact that on the $30^{\text {th }}$ day the animals of control series were superior to experimental rats as the amount of bone tissue was concerned, $16.39 \pm 0.93 \%$ of the total area of the defect in the latter group was occupied by the osteoplastic material which had not yet undergone resorption and therefore could not be replaced by the bone tissue of the regenerate.

According to the present study, the application of the osteoplastic material Collapan in the area of femoral diaphyseal defects in rats had beneficial effects, consisting in optimisation of reparative osteogenesis, high biocompatibility, better osteoconductive properties, resorption ability and good integration with tissuespecific structures of the regenerate.

\section{REFERENCES}

Barer, G. M., T. P. Vavilov \& A. S. Tumanov, 2004. The use of the biocomposite drug "CollapAn" containing various antibacterial inclusions on the surgical stage of complex treatment of periodontitis. Kafed$r a, 10,45-49$ (RU).
Barinov, S. M. \& V. S. Komlev, 2005. Bioceramics based on calcium phosphates, Nauka, Moscow (RU).

Berchenko, G. N., G. A. Kesyan, R. Z. Urazgildeev, I. G. Arsenyev \& D. S. Mikelaishvili, 2006. Comparative experimental morphological study of the effect of some calcium phosphate materials used in trauma and orthopedic practice to activate reparative osteogenesis. Bulletin of the East Siberian Scientific Center, Siberian Branch of Russian Academy of Medical Sciences, 4, 327-333 (RU).

Bushuyev, O. M., 1999. CollapAn use in treatment of chronic osteomyelitis. $\mathrm{PhD}$ Thesis (Abstract) Moscow, $21 \mathrm{p}$ (RU).

Dorozhkin, S. V., 2013. Calcium orthophosphate-based bioceramics. Materials, 6, 3840-3942.

Dorozhkin, S. V., 2015. Calcium orthophosphate-containing biocomposites and hybrid biomaterials for biomedical applications. Journal of Functional Biomaterials, 6, 708-832.

Germanov, V. G., G. M. Kovalersky, Z. A. Cherkashena \& V. A. Semenov, 2006. Osteoplastic surgery: From bone transplant to the modern biocomposite materials. Medical Assistance, 4, 16-19 (RU).

Grigorian, A. S. \& A. K. Toporkova, 2007. Problems of Integration of Implants in Bone Tissue (Theoretical Aspects). Technosphere. Moscow (RU).

Iordanishvili, A. K, V. G. Gololobov, S. E. Baschenko \& N. V. Sakharov, 2002. "Collapan" - a modern optimizer of reparative osteogenesis. Outpatient Surgery. Hospital-replacing Technologies, 2, 6-8 (RU).

Jenkins, M. J., 2011. Polymers in Biology and Medicine, Scientific world, Moscow (RU).

Kavalersky, G. M., A. I. Protsenko \& V. K. Nikuradze, 2013. CollapAn in Surgery of Injuries and Diseases of the Cervical Spine, Printing House HT-print, Moscow (RU).

Lapach, S. N., A. V. Hubenko \& P. N. Babich, 2000. Statistical Methods in Biomedical 
Healing of experimental femoral defects in rats after implantation of collagen-calcium phosphate....

Research Using Excel, Morion, Kiev (UKR).

Pankratov, A. S., M. V. Lekishvili \& I. S. Kopetsky, 2011. Bone Grafting in Dentistry and Maxillofacial Surgery. Osteoplastic Materials: A Guide for Physicians, BINOM, Moscow (RU).

Park, J. B. \& J. D. Bronzino, 2003. Biomaterials: Principles and Applications. Boca Raton: S. R. C. Press, Florida.

Rublenko, M. V. \& S. A. Semenyak, 2014. Biomarkers of reparative osteogenesis in dogs after osteosynthesis and using biocomposites. Veterinary Medicine, 98, 137140 (UKR).

Semenyak, S. A., 2014. Prospects of use of biocomposite materials for comminuted fractures of tubular bones in dogs. Veterinary Medicine of Ukraine, No 9, 27-29.

Semenyak, S. A., M. V. Rublenko \& V. B. Dudka, 2015. Clinical and morphologic characteristics using of osteotropic materi- als to replace bone defects in animals. Veterinary Medicine, 100, 157-161 (UKR).

Snetkov, A. I., S. Y. Batrak, A. R. Frantov \& A.M. Avakian, 2006. Applications of implant "CollapAn" in the clinic of pediatric bone pathology. Biomaterials, 5, 2-4.

Paper received 23.10.2015; accepted for publication 22.01.2016

\section{Correspondence:}

Oleksiy Korenkov,

Department of Human Anatomy, Sumy State University,

31 Sanatorna str 40000 Sumy, Ukraine, phone.: +38066-843-65-03, e-mail: korenkov-alexsey@mail.ru 